\title{
A Review on the Conductive Properties of Graphene Oxide Films
}

\author{
Vladimir Vasiliev*, Vyacheslav Smirnov \\ The Institute of Problems of Chemical Physics of the Russian Academy of Sciences (IPCP RAS), Acad. Semenov \\ ave. 1, Chernogolovka, Moscow region, 142432, Russia
}

*Corresponding Author: Vladimir Vasiliev, the Institute of Problems of Chemical Physics of the Russian Academy of Sciences (IPCP RAS), Acad. Semenov ave. 1, Chernogolovka, Moscow region, 142432, Russia

\begin{abstract}
Current-voltage characteristics of graphene oxide $(G O)$ films were explored in water vapor as a function of water content in the film. The films can contain free and bound water. A decrease in current with time at a constant voltage is associated with the decrease in water content. Reduced GO (rGO) films exhibited proton and electron conductivity. For the proton conductivity $E_{a}=0.9 \mathrm{eV}$, for the electron conductivity induced by thermolysis and chemical exposure $E_{a}=1.15 \mathrm{eV}$. The rGO films is an example of mixed electron-proton conductivity when material conductivity can be regulated by external conditions. The field effect in a graphene oxide transistor for different conductivity types has been discovered and investigated. The possibility of accumulation and storage of electric charge in Nafion and GO films was demonstrated for the first time. The storage is governed by humidity of ambient environment. Charge accumulation occurs directly in Nafion or GO films.
\end{abstract}

Keywords: Graphene oxide/Nafion film, Current-voltage characteristics, Proton conductivity, Mixed protonelectron conduction, Diffusion, Field effect, Dry charged battery

\section{INTRODUCTION}

After isolation of individual graphene nano sheets in 2004, the worldwide interest to graphene and graphene-like materials was drastically increased. Today, graphene-like materials with graphene properties are considered be obtained in large amounts from graphene oxide which is easily synthesized from graphite in 'mild' conditions. Graphene oxide (GO) was initially considered as a source product for the production of grapheme. However, GO itself is the subject of active studies to be used in various materials and devices [1-8].

A search for new proton conductors is of high interest since such materials can be used for fabrication of new devices different from those based on conventional electron conductors. Materials with proton conductivity are used in various devices [9]: fuel cells, electrolysis cells, electrochemical sensors, electrochemical reactors, electrochromic devices. Proton transport is observed in biological systems. In the dry state GO is an insulator, and in a humid atmosphere GO demonstrates proton conductivity [10-12]. On the other hand, GO itself is a promising material for various applications. As a proton conductor GO is applied in humidity sensors [10, 14], in supercapacitors [15-16], as well as in a fieldeffect transistor [10,17], and nano composite membranes [18-21]. There is a possibility to integrate $\mathrm{GO}$ in graphene electronic devices [22]. Moreover, GO is utilized in hydrogen-accumulating materials [23]. GO is known to be a dielectric but possesses a proton conductivity. It should be noted, that properties of GO films are expected to depend markedly on the morphology of the film, especially in the case when GO flakes contain more than ten nano sheets $(n>10)$. This peculiarity is determined by the fact that GO nano sheets are not planar and distributed randomly. In addition, GO films operate at temperatures at which polymer proton conductors do not operate.

The behavior of interlayer water was studied in detail for graphite oxide [24-26]. By using neutron scattering, it has been shown [24] that, in the interlayer space, water may exist at high humidity in two forms: translational motion capable form and translational motion incapable one. The interlayer distance in graphite oxide was found [25] to abruptly change in the vicinity of freezing point. Talyzin et al. [25] have also established the presence of two types of water in the interlayer space of graphite oxide. The same conclusion was also reached by Zhu et al. [26] who investigated the thermal expansion of graphene layers and explained the negative thermal effect by reversible diffusion of free 
water in the layered assembly of GO: adsorption of water at low temperatures and its desorption at higher temperatures. GO is also known to contain the bound water. Graphite oxide and graphene oxide may have different structures: one is formed by ordered graphene layers while another, by randomly arranged GO nano sheets. But the literature data suggest that water in both interlayer spaces behaves similarly.

Several phenomena affecting the electrical properties of the films were disclosed in our previous studies $[27,28]$ on the photoconductivity of GO films in water vapor. At the initial stages of exposure to water vapor, the current was found to grow due to the presence of free water in the film. Then, during experimental run at constant applied voltage and temperature, the current gradually decreased, which was attributed to changes in the film morphology.

High ion conductivity combined with low electron conductivity is an important parameter of the electrolyte membrane. The Nafion was developed by DuPont in the 1960s. The proton conductive Nafion membranes are widely used in fuel cells [29]. Nafion is a polymer with high proton conductivity and adjustable swelling in water [30, 31]. Commercial cation-exchange membranes have following characteristics: the typical thickness is $50-200 \mu \mathrm{m}$, the conductivity $\sigma$ is $0.005-0.003 \mathrm{~S} / \mathrm{cm}$ at $100 \%$ relative humidity. Nafion polymer possesses high chemical and electrochemical stability, its proton conductivity is high after complete hydration; in a dry state, however, Nafion films do not operate effectively. The state of water in Nafion film was considered in [32], and the film were concluded to contain water in two states: free and bound water.

In the work $[13,27,28]$ the proton conductivity of multilayer films of GO was studied and it was noted $[27,33]$ that photoreduction of GO leads to the onset of electronic conductivity accompanied by concomitant decay of protonic conductivity. Materials with mixed conductivity type are used in various devices, as discussed in the review articles [34-36]. Electron-ion conductivity in inorganic materials [34] and electron-proton in conducting polymers [35, 36] is generally regarded as the total conductivity in these materials. A recent trend is the development of composite materials comprising of two components exhibiting the proton and electronic conductivity. In such composites, the role of matrix is usually played by Nafion while that of electron-conducting component, by reduced graphene oxide [37], carbon nanotubes [38], and metal hydrides [39]. In these materials electron conductor is actually a foreign body in the Nafion matrix so that the electronic conductivity of the material depends on the quality of contact between the constituents. In wet conditions the proton conductivity can be expected to grow while the electronic one, to decrease due to insulation of particles with electronic conductivity. In contrast to composites, GO is a homogeneous material but in OG films exhibiting proton conductivity in wet conditions $[13,27,28]$ it seems feasible to induce electronic conductivity under the action of external influences, such as thermal treatment, chemical processing, and UV irradiation.

Field effect (FE) in transistors with a thin 2D carbon canal up to the graphene monolayer, landed on the surface of single-crystal plate oxidized silicon was implemented and studied in detail in the fundamental work K.S. Novoselov, A.K. Geim et al. [40]. The paper was also studied magnetic phenomena in these transistors. This work caused the explosive interest in objects such as graphene, and results of researches can be found in review articles [41-43]. Researches of FE transistors based on graphene and oxidized silicon performed in [45-47]. The article [44] reports about field effect on the reduced graphene oxide monolayer, and this effect is several percent. In [45] the mobility of charge carriers was investigated in a wide temperature range. In [46] a shift of the Dirac point for graphene surface treatment by electron beam of $30 \mathrm{keV}$ is observed. In [47] in FE transistors the modified graphene (heterostructure) is used that allowing to change the current 4-5 orders of magnitude by gate voltage. In [48] using of the graphene oxide as an insulating layer is proposed. The use graphene oxide in the FE transistor considered in [49]: the conductive layer graphene are created on the layer of GO by hydrogen plasma and GO served as an insulating layer on the gate. Graphene oxide was also used as an insulating layer in a transistor deposited on a flexible plastic, wherein the active layer and electrodes graphene are used [50].

\section{EFFect of InTERlayer Water in Graphene OXIDE ON Proton CONDUCTIVITY}

The GO films deposited onto the electrodes and dried at room temperature exhibited proton conductivity in water vapor $[27,28]$. Figure 1 shows the behavior of current $I$ in a GO film at 
variation in relative ambient humidity $(R H)$. The protonic conductivity linearizes in the $\log I-R H$ coordinates.

The evolution of current $I$ was found to depend on drying conditions, applied voltage, and ambient humidity (see Figure 2). At room temperature and $R H 7 \%$, practically no current was observed (for $U<10 \mathrm{~V}, I<1 \mathrm{nA}$ ), and it arose at $R H 100 \%$. The polarization component exhibits a maximum for $t$ around $200 \mathrm{~s}$, and its magnitude depends on the amount of residual free water in the GO film [27, 28].

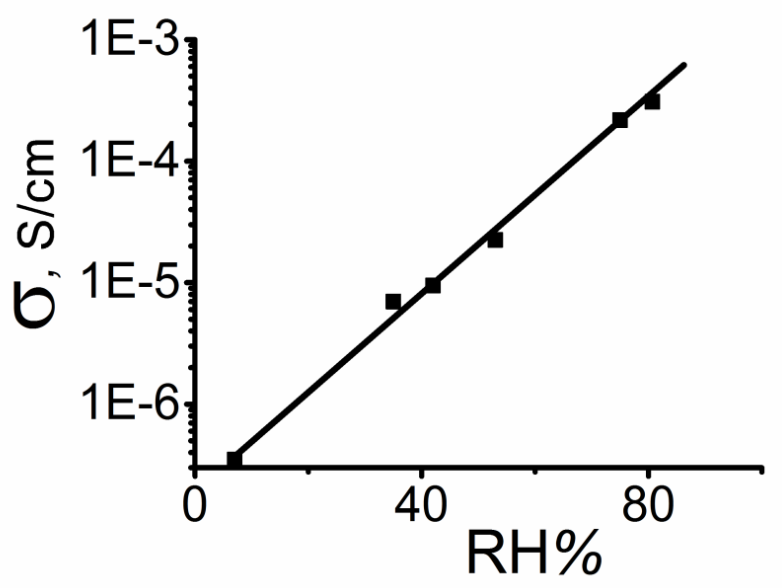

Figure1. Behavior of current I in a GO film at variation in relative humidity $(U=500 \mathrm{mV})$.

Drying at $R H 7 \%$ decreases the amount of unbound free water in the film and the polarization current is gradually decreases down to complete disappearance of polarization peak. Subsequent behavior of the current is controlled by the diffusion of water molecules in the GO film (proton conductivity [27, 28]), and the current reaches its maximum value and then decreases within a period of several hours. When dried at $R H 7 \%$ for above $2 \mathrm{~h}$, the polarization current is virtually absent and the observed current is due to protonic conductivity due to water diffusion into the GO film and residual bound water. Prolonged drying at $R H 7 \%$ reduces the maximum current, thus indicating the removal of bound water from the GO film during its drying. For example, after drying for $2 \mathrm{~h}$ the maximum current measured at $U=1 \mathrm{~V}$ and $R H 100 \%$ is $640 \mathrm{nA}$; after drying for $18 \mathrm{~h}, 240 \mathrm{nA}$; and after drying for $42 \mathrm{~h}, 155 \mathrm{nA}$. Further drying for $2 \mathrm{~h}$ in vacuum $\left(10^{-1} \mathrm{~Pa}\right)$, practically no current was found even at $R H 100 \%$. A significant suppression of diffusion caused by elimination of interlayer water can be regarded as an indication of marked changes in the film morphology, since there were no concomitant chemical transformations.

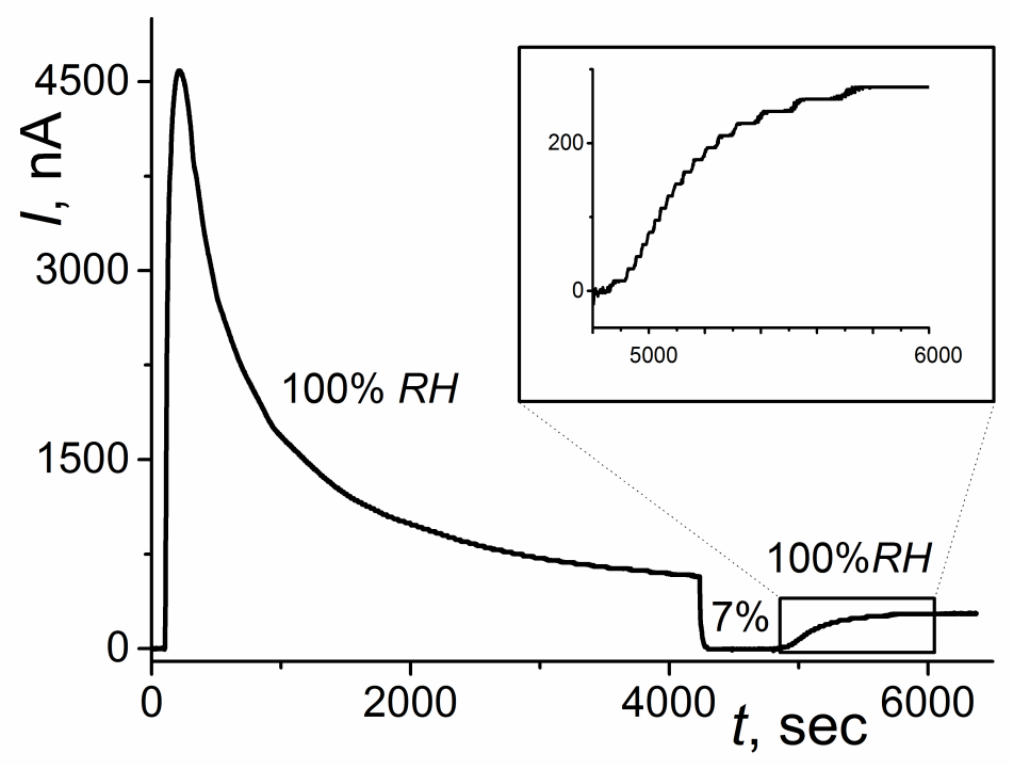

Figure2. Behavior of current I after drying at RH 7\% for $1 \mathrm{~h}(U=10 \mathrm{~V})$. 
More unusual seems a significant current drop when the cell is placed in water vapor. Such a behavior can also be explained by the removal of bound water and change in the film morphology. We did not observe any signs of GO reduction or the appearance of any additional current (electronic conduction) or sample blackening. After transfer from water vapor to $R H 7 \%$, the current dropped down to zero $\left(I<10^{-9} \mathrm{~A}\right)$. When returned into water vapor, the current resumed but the back diffusion of water molecules into the film was slower by one order of magnitude because of some change in the film morphology.

Figure 3 shows the temporal profiles of current $I$ obtained at different $U(R H 100 \%)$. The insert shows the normalized curves. It follows that the kinetic curves at different voltages are markedly different: the decay time grows with decreasing $U$. These experiments also imply that we may neglect the electrolysis of water in the film because the current decline is observed even at $U=0.1 \mathrm{~V}$ when electrochemical reactions [51] can hardly be expected to occur. It should also be noted that similar processes were also observed in thicker films $(200-500 \mathrm{~nm})$, their duration growing with increasing film thickness.

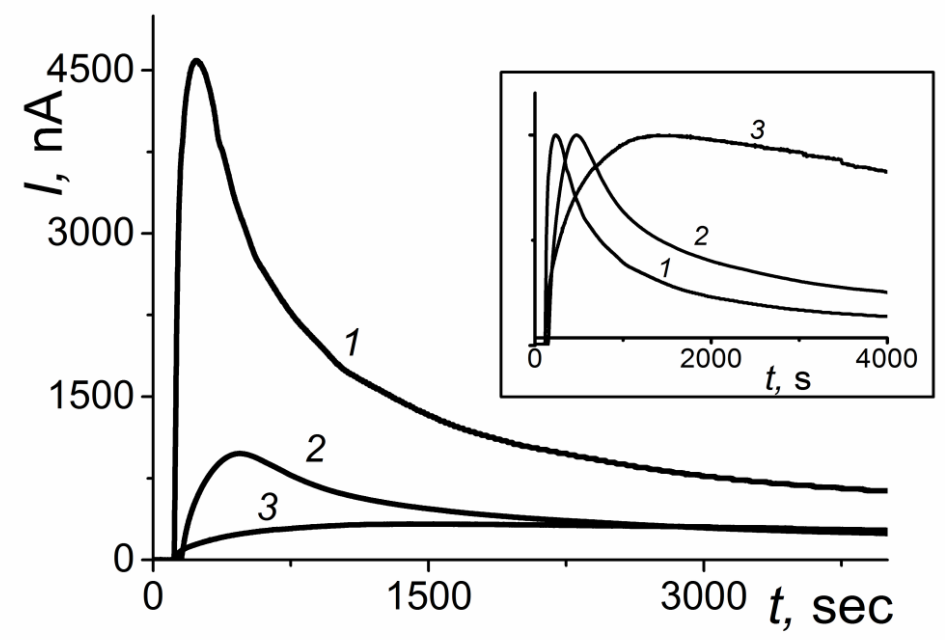

Figure3. Temporal profiles of current I (RH 100\%) obtained at $U=10(1), 2(2)$, and $0.1 \mathrm{~V}(3)$. The normalized curves are given in the insert.

Figure 4 shows the IR spectra of GO films. It follows that either drying at $R H=7 \%$ or in vacuum or passing current had little or no influence on the IR spectra. But we managed to observe some spectral changes in the presence of free water in the film at $U>5 \mathrm{~V}(\mathrm{E}>150 \mathrm{~V} / \mathrm{cm})$ applied for rather long time periods. This can be associated with partial electrochemical reduction of GO reported for aqueous solutions [51].

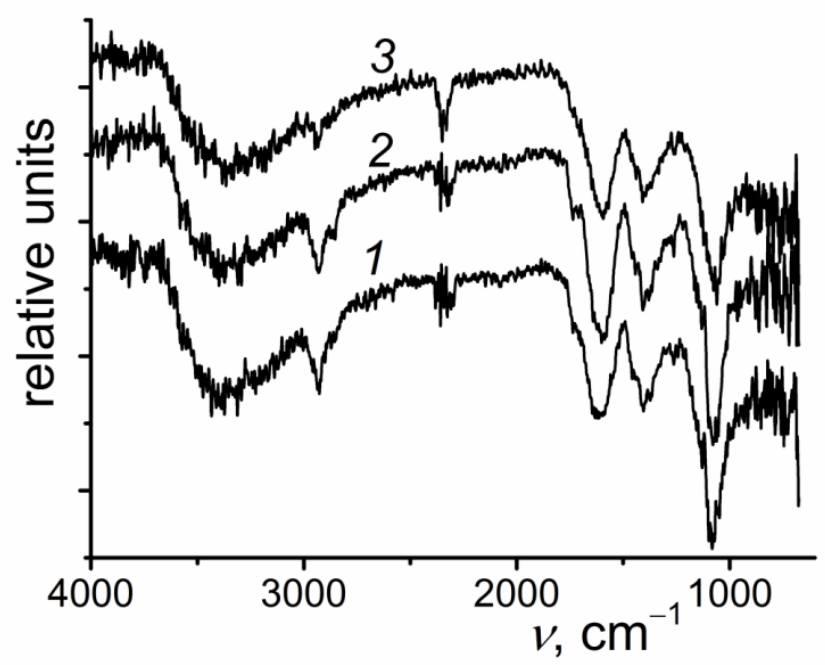

Figure4. IR spectra of GO films: (1) immediately after drying at RH 7\% for $18 \mathrm{~h}$; (2) after drying in vacuum $\left(10^{-1} \mathrm{~Pa}\right)$; and (3) after holding at voltage $U=1 \mathrm{~V}$ for $6 \mathrm{~h}$. 
We also observed electronic conductivity after GO reduction. The latter was done in several ways: (a) by UV irradiation, (b) by heating, and (c) by chemical means [27, 28, 51, 52]. In all cases the electronic conductivity was observed in dry samples. Figure 5 shows the $I-U$ characteristics of GO films $(R H 7 \%)$ after reduction. The characteristics are seen to be linear and this property was also exhibited by samples subjected to longer reduction times. At initial stages of reduction, some contribution from proton conductivity could be observed at room-temperature humidity.

The linearity of current-voltage characteristics are consistent with the literature data [53] on oxidation of multilayer graphene layer (300 nm thick) with oxygen plasma; in this case the conductivity changed but the current-voltage characteristics remained linear.

It should be noted that the diffusion of hydrazine molecules into the GO film at room temperature was much slower than that of water molecule. After 10 hours holding in hydrazine vapor, we noticed the occurrence of film blackening, growing with exposure time, but the conductivity in $100 \mathrm{~nm}$ films appeared only after 70 hours of exposure, when hydrazine molecules reached the near-electrodes space.

As is seen from Figures $2-3$, current $I$ decreases gradually with time. This can be regarded as a consequence of film "compaction" caused by infiltrated water molecules. This implies that the diffusivity of water molecules changes during experimental run. In this work, we made an attempt to solve the inverse problem, that is, by using the equation of diffusion we estimated the diffusion coefficient of water molecules in the system under study on the basis of our experimental data.

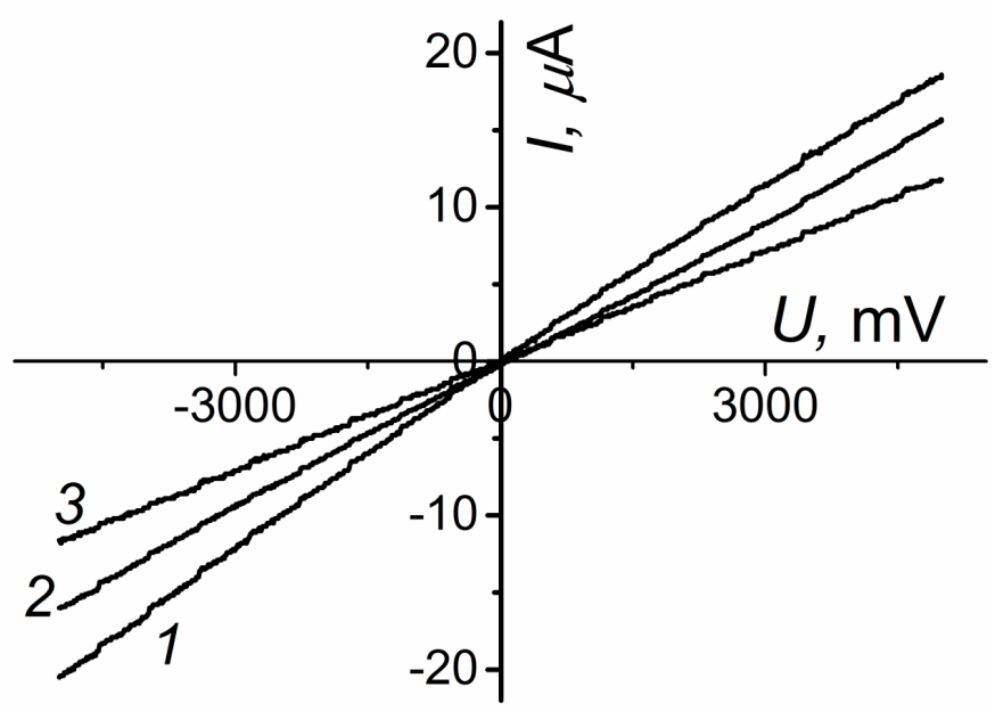

Figure5. The I-U characteristics of GO films (RH 7\%) after GO reduction: (1) by UV irradiation (260-390 $\mathrm{nm}$, $3 \mathrm{~h}),(2)$ by annealing at $130^{\circ} \mathrm{C}$ for $3 \mathrm{~h}$, and (3) by exposure in hydrazine vapor $\left(25^{\circ} \mathrm{C}, 75 \mathrm{~h}\right)$.

Therefore, multilayer GO films can exist in three states: (a) as completely dry, (b) as containing bound water, and (c) as contains both bound and free water. Water can be eliminated by passing electric current in a humid atmosphere. There are three levels of hydration in the membrane: (a) completely dry, (b) minimal hydration; and (c) complete hydration [32].These states can significantly affect the membrane diffusivity.

Removal of the interlayer water may also affect the film thickness. However, we did not find any signs of such influence in the films up to $500 \mathrm{~nm}$ thick, neither in Newton's rings nor in color/position change. Ellipsometric analysis [54] suggests that the removal of interlayer water from multilayer GO films $(n=1-4)$ leads to a $20 \%$ decrease in film thickness; but in our case $(n>10)$ this effect was unnoticeable.

\section{Mixed Proton and Electron Conductivity in Reduced Graphene Oxide}

\subsection{Proton Conductivity}

The GO films deposited on the electrodes and dried at room temperature reveals conductivity in wet conditions [28], the GO films cast onto a substrate are known to exhibit the electro conductivity of 
typical proton conductors $[13,28,55]$. Figure 1 shows typical behavior of current $I$ in a GO film at variation in relative humidity $(R H)$. Changes in proton current $I$ at stepwise variation in applied voltage $U(\Delta U=50 \mathrm{mV}, R H 53 \%)$ are presented in Figure 6. It follows that current $I$ is proportional to applied voltage $U$.

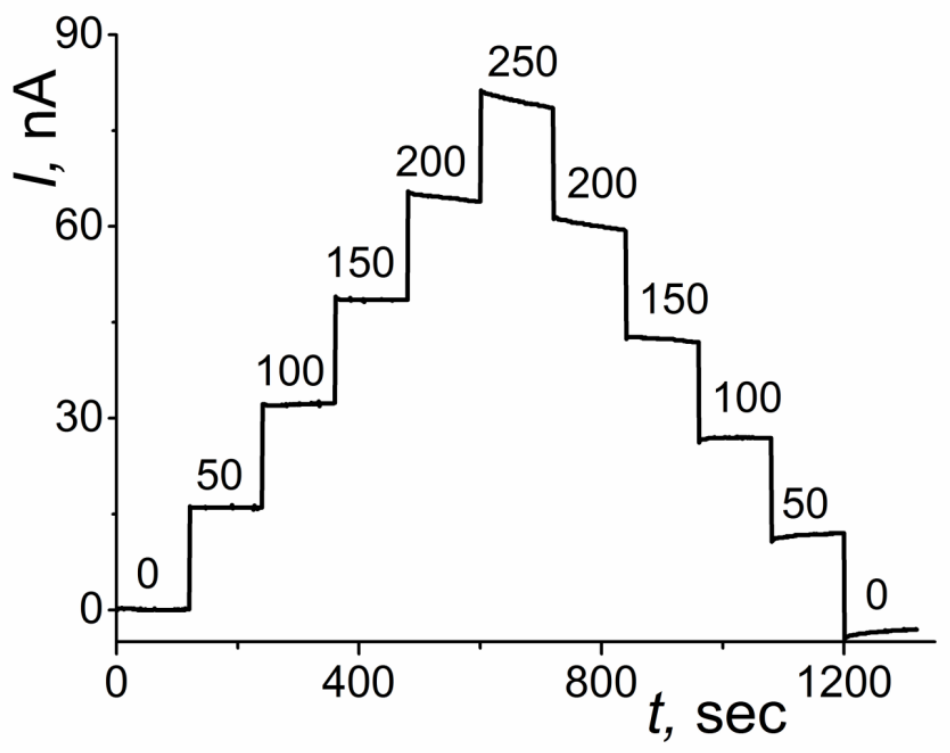

Figure6. Changes in protonic current I upon stepwise variation in applied voltage - U (RH 53\%).

The temperature dependence of proton conductivity $\sigma$ was found (Figure 7) to linearize (for $T>0{ }^{\circ} \mathrm{C}$ ) in the Arrhenius coordinates with the activation energy $E_{\mathrm{a}}=0.9 \pm 0.05 \mathrm{eV}$. The latter is close to that $(0.83 \mathrm{eV})$ reported for the membranes made of GO paper [56]. The close value of $E_{\mathrm{a}}=0.78 \pm 0.03 \mathrm{eV}$ was found for proton transport through a one-atom-thick graphene layer [57].

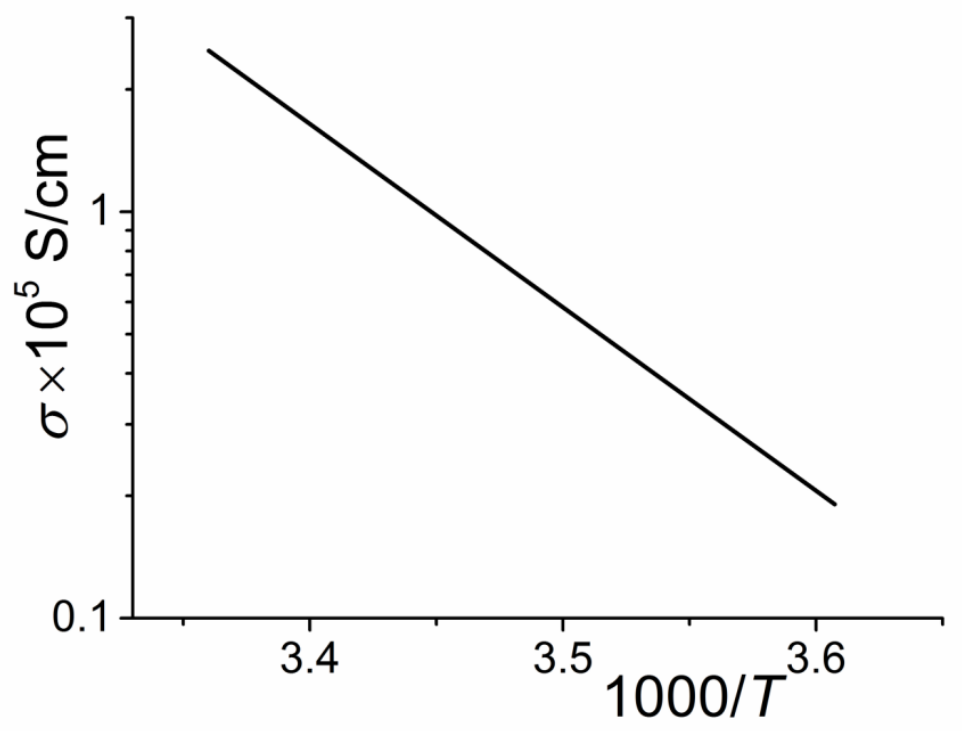

Figure7. Temperature dependence of protonic conductivity $\sigma$ as plotted in the Arrhenius coordinates (RH 75\%, $U=300 \mathrm{mV}$ )

\subsection{Electron Conductivity}

After partial reduction of GO, our films exhibited also electron conduction. Cells with GO film are dried and reduced in several ways: chemically and thermally: in all cases the electronic component of current is occurred in the dry samples. Figure 5 shows the $I-U$ characteristics of GO films (at $R H 7 \%$ ) after partial reduction of GO: (1) by thermal treatment at $130^{\circ} \mathrm{C}$ for $3-4$ hours, (2) by chemical means in the pair of hydrazine at 50-75 hours at a temperature of $25-60^{\circ} \mathrm{C}$ (treatment conditions were adjusted to get comparable current characteristics). 
The linearity of the $I-U$ characteristics did not depend on the duration of each reduction procedure. At the initial stages of reduction (when contribution from electron conduction is low), some non-linearity may be introduced by proton conduction depending on the ambient humidity. The linearity of our $I-U$ characteristics agrees with the results [53] reported for structurally defected multilayer graphene films (300 $\mathrm{nm}$ thick) after their oxidation with oxygen plasma and the conductivity of the layer has changed (decreased) in the oxidations process but the current-voltage characteristics remained linear.

The temperature dependence of electronic conductivity $\sigma$ was found (Figure 8) to linearize (for $T<$ $0^{\circ} \mathrm{C}$ ) in the Arrhenius coordinates, irrespective of the type of reduction method, under these conditions the water is frozen and there is no proton conductivity. For chemical and thermal reduction the activation energies were estimated as $E_{\mathrm{a}}=1.15 \pm 0.05 \mathrm{eV}$ in both cases. In the temperature range $220-273 \mathrm{~K}$, our conductivity results well fit the exponential dependence $\sigma \sim \sigma_{0} \exp (-\Delta E / \mathrm{k} T)$. This implies that the conductivity is governed by a single barrier, which is the case for typical semiconductors. In amorphous materials, such as conductive polymers the temperature in the exponent must have a power relationship of the type $T^{1 / n}$, where $n$ ranges from 1 to 3 . But this dependence is manifested at low temperatures, which is not investigated in our case.

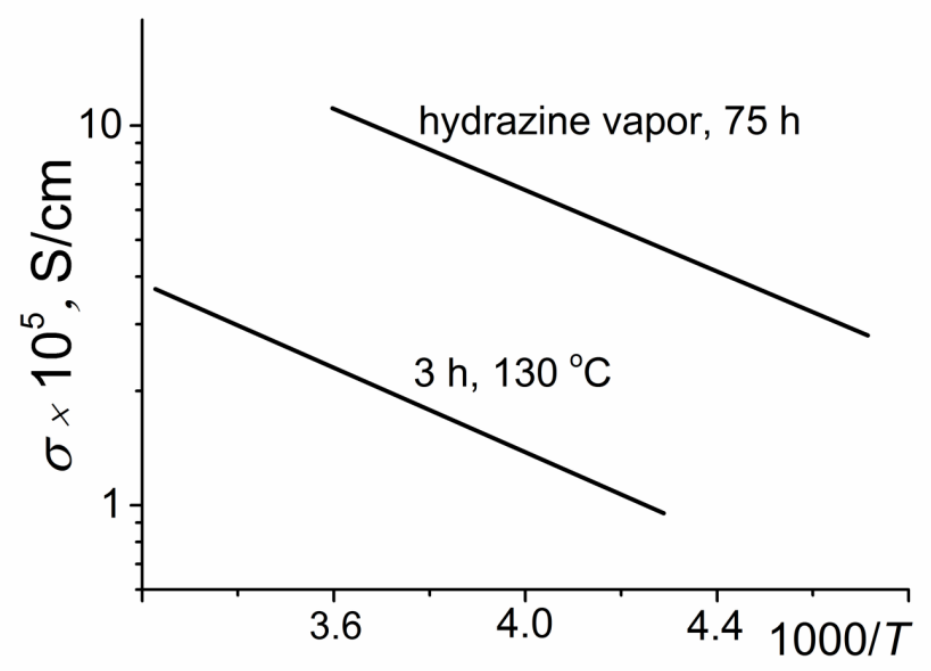

Figure8. Electron conductivity $\sigma$ vs. $1000 / T\left(T<0^{\circ} \mathrm{C}\right)$ for GO films after their reduction.

\subsection{Mixed Conductivity}

Partially reduced GO films exhibited both electron and proton conduction: in dry conditions at $R H 7 \%$ it is electronic conductivity while in wet conditions ( $R H 35 \%$ ), it is protonic one (Figure 9). Applying voltage $U$ to partially reduced GO at $R H 7 \%$ gives rise to electron current $I_{\mathrm{e}}$ (Figure 9). After sample transfer to wet conditions ( $R H 35 \%$ ), current $I$ is seen to sharply decrease.

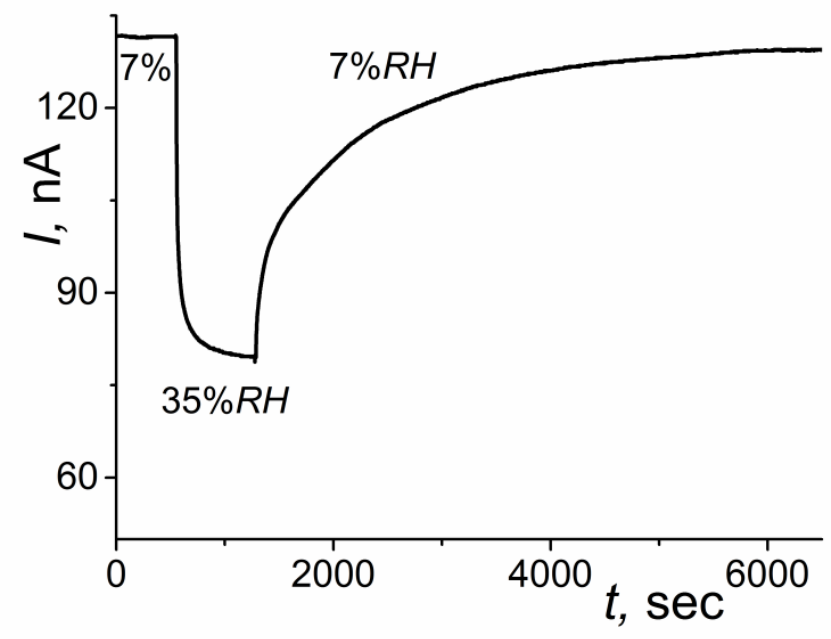

Figure9. Behavior of current I through a GO film partially reduced in hydrazine vapor. 
At the first glance it looks strange since, according to Figure 1, this must be accompanied by the onset of proton conduction. In contrast to inorganic crystals with mixed electron-hole conduction where the above currents are summarized, in our case they are deducted. Sample return to ambient humidity restores the electron current up to its initial level.

Figure 10 illustrates the behavior of current $I$ through a GO film upon variation in $R H$ after chemical reduction to different starting values of $I_{\mathrm{e}}$. As is seen in Figure 10, after the first stage of reduction (to $I_{\mathrm{e}}=107 \mathrm{nA}$ ) an increase in $R H$ initially decreases current $I$ and then causes its growth: this implies that the proton conductivity becomes larger than the electronic one. Upon further reduction to $I_{\mathrm{e}}=140$ nA (Figure 10), the overall view of the $I(R H)$ function markedly changes because the electron conductivity becomes larger than the proton one even at high $75 \% R H$. The GO is converted in graphene material after a long reduction and current in the film becomes is due to the electronic component only and it independent of humidity essentially.

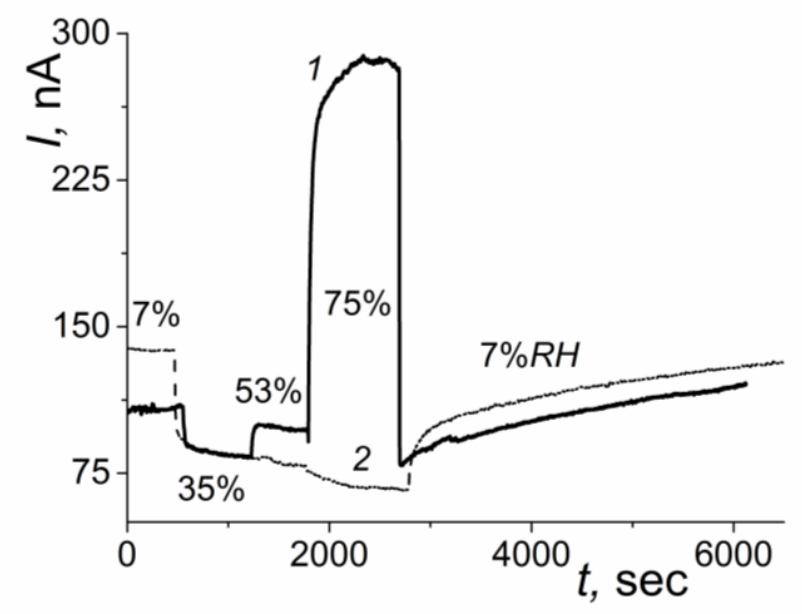

Figure10. The dependence of the total current in the GO film on the humidity after GO reduction in hydrazine vapor: (1) partial reduction in hydrazine vapor to $I_{e}=107 \mathrm{nA}$ and (2) additional reduction to $I_{e}=140 \mathrm{nA}$.

It should be noted that the electronic component is not fully compensated by the proton one. This means that the channels for electron conduction appear in the GO film after any kind of treatment due to $\mathrm{sp}^{2}$-hybridization, and such channels cannot be closed by moisture diffusing along the surface of layers with $\mathrm{sp}^{3}$-hybridization with hydroxy- and epoxy-groups. Tentatively, this can be said and about proton conduction: after each kind of processing, the GO film still retains some channels with $\mathrm{sp}^{3}$ hybridization due to the presence of hydroxy and epoxy groups suitable for diffusion of water molecules and hence for proton conduction. Such channels do not overlap. But in some film areas the domains of electron and proton conductivities may nevertheless overlap.

Since in wet conditions GO films behave as typical proton conductors [27, 53, 55], the effect of mixed conduction can be exhibited by other materials with simultaneous electron and proton conductivity. Similar decrease in electron conduction with increasing humidity observed for composite materials [37-39] was associated with insulation of GO particles at moisturizing.

\section{Field Effect in a Graphene Oxide Transistor for Proton and Electron-Hole CONDUCTIVITIES}

\subsection{Relaxation Processes In GO Films}

The difference between the properties of the electron and the proton conductivity effects on relaxation processes. Figure 11 shows the transient current characteristics of a step change of voltage on the sample. Curve 1 corresponds to the change of the electron current in a partially reduced film of GO when applying a voltage $+1 \mathrm{~V}$ and $-1 \mathrm{~V}$ to the electrodes in one-minute intervals. It can be seen that the curves of changes in the currents quire, which is typical for the inertia less current component in the sample. The protonic constituent comparable with electronic conductivity appears when placing the same sample in a humid atmosphere of 53\% RH (curve 2). The transient characteristics manifested relaxation component of the current. Further increase in humidity to $75 \% \mathrm{RH}$ (curve 3) significantly increased the current and the proton relaxation component becomes comparable to stationary current. 


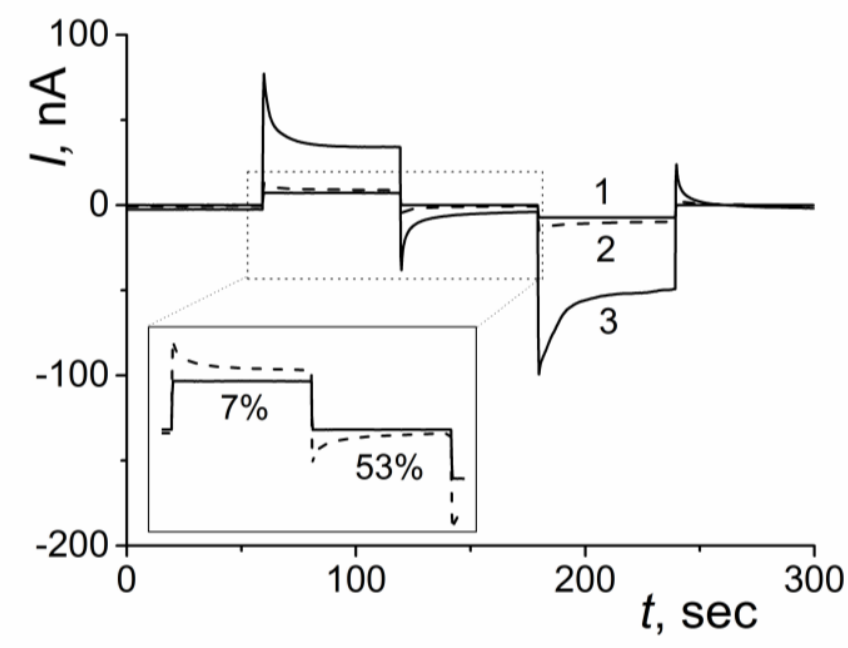

Figure11. Transient current characteristics at a step change in the voltage of +1 and- $1 \mathrm{~V}$, the interval of 60 seconds. 1 -electronic conductivity of the GO film RH 7\%; 2 - conductivity at 53\% RH; 3 - conductivity at 75\% RH.

Relaxation (Figure 11) is not described by monoexponential dependence, and the relaxation time (at half height) is several seconds. Dipole polarization of water molecules and charged fragments with the attached water may be responsible for such processes. Relaxation is due not only to the electronic component, but also the structural, that is their rotating and partial displacement. Such fragments maybe, e.g., $\mathrm{H}_{2} \mathrm{O}_{2}$-groups arising during attachment of water molecules to the hydroxy group and the proton of the group participates in conduction. Our transient characteristics are consistent with the frequency dependency of the impedance measured for GO films at various humidity [10]: the amplitude of impedance decreases with increasing of frequency and with increasing of environments humidity.

\subsection{Model of Field Effect Transistor}

The presence of two types of conduction in the GO films can be shown by using the GO in the circuit of field effect transistor. Field effect was studied both for a proton and an electron-hole conductivities of GO in the transistor circuit shown in Figure12. The GO film thickness was about1 $\mu \mathrm{m}$, the thickness of the $\mathrm{SiO}_{2}$ is $0.1 \mu \mathrm{m}$, the voltage $U_{\text {sd }}=1 \mathrm{~V}$, the gate $(\mathrm{G})$ was applied step voltage from 0 to $\pm 12 \mathrm{~V}$ in $1.5 \mathrm{~V}$.

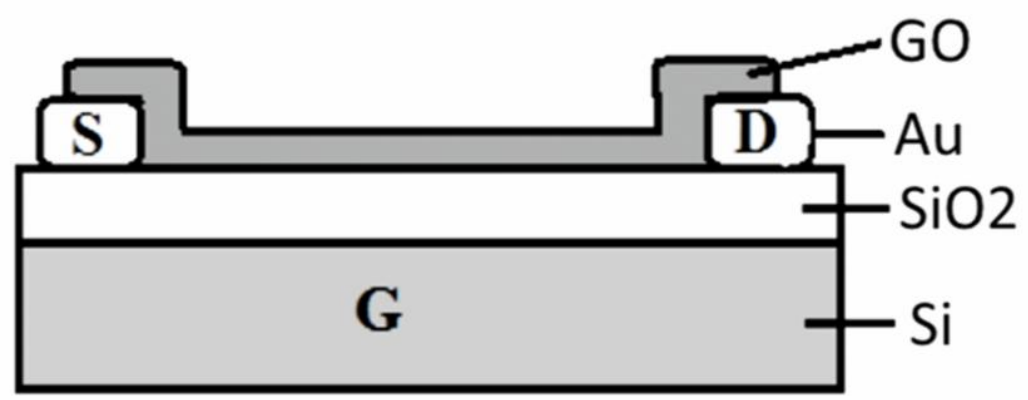

Figure12. The schematic diagram of transistor.

Figure 13 shows the current characteristics of the proton conductivity of the transistor- it is not reduced GO is present in the sample only and electronic conductivity is absent. There is no current ( $I$ $<1 \mathrm{nA}$ ) even when applied to the gate voltage $U_{\mathrm{g}}$ of -12 to $+12 \mathrm{~V}$ in a dry atmosphere at the sourcedrain voltage $U_{\text {sd }}=1 \mathrm{~V}$. At placing transistor in a humid atmosphere $75 \% R H$ the current appears in a sample due to proton conductivity (Figure 1). The current reaches saturation after about a minute and then voltage negative step is applied to the gate. The supply negative voltage substantially increases the current. At a positive voltage to the gate this current of the transistor begins to decrease (after 300 s) and even changes sign when the $U_{\mathrm{g}}=6 \mathrm{~V}$. As can be seen from Figure 13, every time you switch the gate voltage relaxation phenomena occur-current peaks with a gradual decline to steady-state current value. 
The subsequent partial reduce of GO leads to the appearance of electron-hole conductivity (Figure 14). The initial current $I_{0} \approx 120 \mathrm{nA}$ and the current depends on the degree of reduction of the GO. Field effect in this case significantly changes the amplitude of response when applying positive voltage to the gate the increase in transistor current (right peak in Figure 14) is observed, which corresponds to the electronic conductivity in the layer of the GO. These currents three orders of magnitude superior to proton conduction currents. It is seen that the current caused to holes (left peak in Figure 14) about twice weaker than the one of electrons and this can be explained by differences in the values of the drift mobility of electrons and holes.

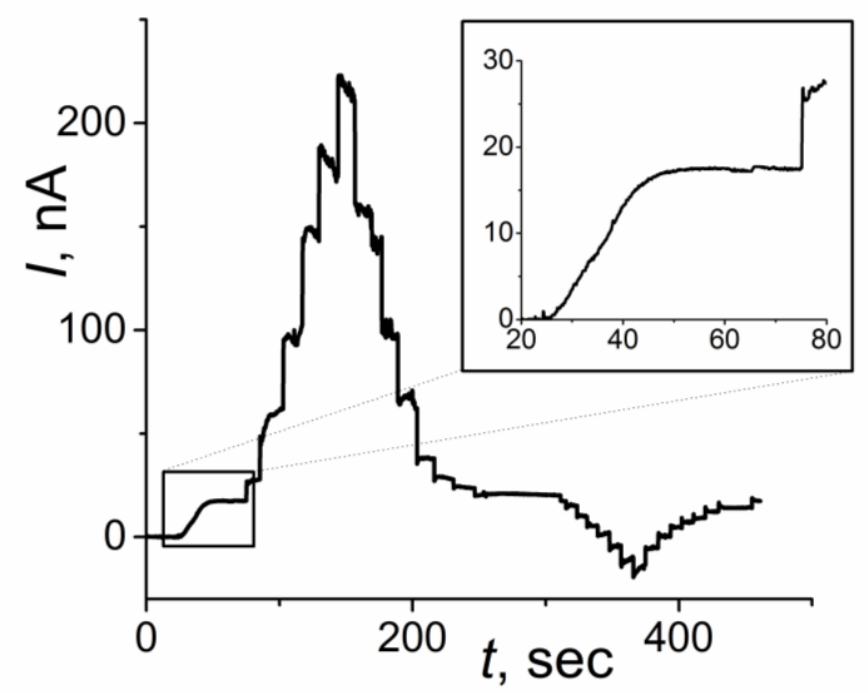

Figure13. The proton conductivity. Current transistor characteristics when placed in a humid atmosphere $75 \%$ $R H$, the gate voltage is changed stepwise in the range $0-(-12 \mathrm{~V})-0-(+12 \mathrm{~V})-0$ step $1.5 \mathrm{~V}, U_{D S}=1 \mathrm{~V}$. (The initial section of Figure).

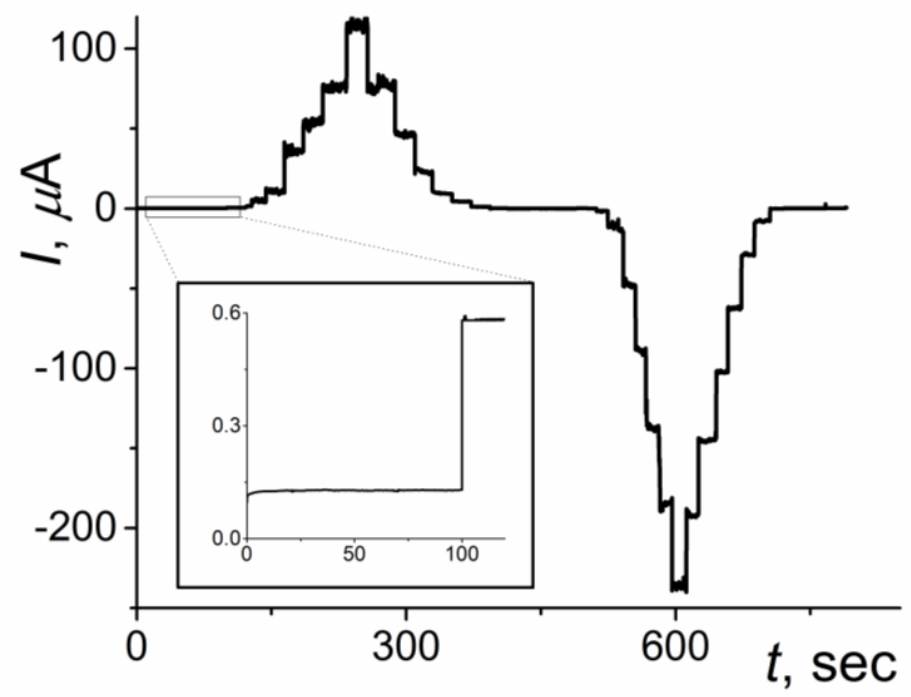

Figure14. The electron-hole conductivity. The current characteristics of transistor in the dry sample $(R H<7 \%)$ after partial reducing of the GO film by hydrazines vapor, electron conduction current $\sim 120$ nA. Measurement conditions are the same as in Figure 13. (The initial section of Figure).

Figure 15 shows the line anamorphosis plots shown in Figures 13 and 14. It should be noted qualitative and quantitative field effect difference between the proton and electron-hole conductivity. First, there is a change in the direction of current upon variation in the sign of voltage applied to the gate: a negative voltage enhances the current of the proton conductivity and a positive voltage increases the electronic conductivity. Secondly, current greatly increases at the electronic conductivity at the same gate voltages compared with proton conductivity - this effect can be explained by the different mobility of charges (electrons, holes and protons) in different cases. 


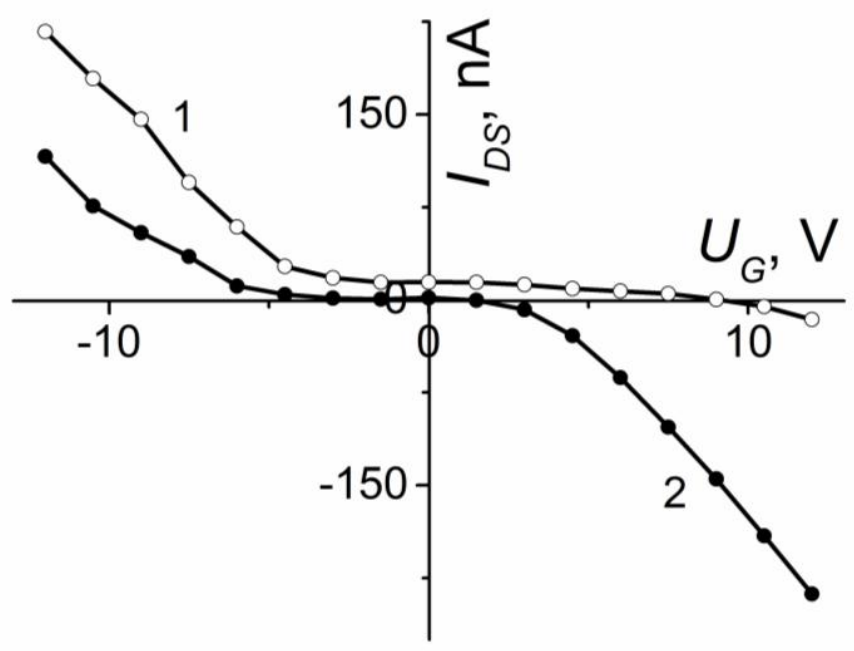

Figure15. The dependence of the current on the transverse electric field at proton (built from the data in Figure 13) (curve 1) and electron-hole conductivity of the transistor (built from the data in Figure 14) (curve 2).

From Figure 15 (curve 1) it is seen that currents determined by proton conductivity at positive offsets remain virtually unchanged and are not of interest. The left branch of this figure (negative bias) allowed us to estimate the concentration of proton conductivity at various displacements. In this case the value of the drift mobility of the protons is taken to be the value obtained in [58] for ice at a temperature of $-5^{\circ} \mathrm{C}: \mu_{\mathrm{p}}=6.4 \times 10^{-3} \mathrm{~cm}^{2} / \mathrm{Vs}$. The concentration of protons at zero bias $\mathrm{n}_{\mathrm{p}}=0.4 \times 10^{17}$ $\mathrm{cm}^{-3}$, and $U_{\mathrm{g}}=-12 \mathrm{~V} \mathrm{n} \mathrm{p}=4.4 \times 10^{17} \mathrm{~cm}^{-3}$, that is, the proton concentration at that off set is increased an order of magnitude. Analysis Figure 11 bat of electron-hole allows to obtain values of the conductivity of the drift mobility of electrons and holes at different $U_{\mathrm{g}}$, based on the total ratio $\sigma=$ $n e \mu$ and considering that $U_{\mathrm{sd}}=1 \mathrm{~V}$. For example, when a bias voltage $U_{\mathrm{g}}=10 \mathrm{~V}$, the electron mobility $\left.\mu_{\mathrm{e}}=1.2 \times 10^{2} \mathrm{~cm}^{2} / \mathrm{Vs}\right)$, and hole mobility $\left.\mu_{\mathrm{h}}=0.6 \times 10^{2} \mathrm{~cm}^{2} / \mathrm{Vs}\right)$, which is approximately two times lower than the electronic one. Note that in [59] the ratio values similar mobility has reversed for the graphene layer, it being the mobility $\left(\mu \approx 10^{4} \mathrm{~cm}^{2} / \mathrm{Vs}\right)$ significantly higher than our values. This is quite natural, since the graphene films have a much more perfect structure than thick (tens or even hundreds of times) films of the GO, which graphene sheets are arranged randomly, and their recovery is made partially.

Our data are consistent with results of other authors on the measurement of the field effect in materials with proton conductivity: polysaccharides [60] and Nafion [61]. Significant field effect in a humid atmosphere is observed in these materials, for example polysaccharides proton conductivity is shown at humidity $R H>50 \%$ [60]. It was shown that at a certain degree of reduction the GO fieldeffect transistor can exhibit either proton or electron-hole conductivity. The transistor currents in the latter case exceed the proton-conductivity currents by about three orders of magnitude. These phenomena can be used for controlling the transistor properties (for example, in sensor and probe circuits). At the same time, the environmental humidity may significantly affect the operation stability of a field effect transistor with GO used as an insulating layer.

\section{Field EFFECT in a NAFION FOR Proton CONDUCTIVITY}

The Nafion films that were deposited on electrodes, dried at room temperature, and then placed in vapor have electric conductivity. A cell with a Nafion film was dried in air and placed in a container with $7 \% R H$ for $10-15 \mathrm{~min}$; in this case, the current was close to zero. When the cell was subsequently placed in water vapor at 53\% $R H$, a current appeared whose behavior is shown in Figure 16. The maximum current is observed on the initial section due to the polarization component (electron and dipole polarization of water molecules), and its strength depends on the amount of residual unbound water in the film, ambient humidity, electrode voltage, and film morphology (this is considered below). The subsequent increase in the current (Figure 16) is caused by proton conductivity due to the diffusion of water molecules into the film. The strength of this current mainly depends on the film morphology (diffusion properties), amount of bound water in the film, and electrode voltage. At high proton conductivity, the polarization peak is absent, and polarization conductivity manifests itself as a sharper initial rise of current. Under the given conditions, there is no 
oxidation of electrodes or chemical transformation of the Nafion film; therefore, this behavior can be explained only by a change in the film morphology, that is, by a change in its diffusion properties with the passage of electric current, which is the subject of the present study. Let us consider the main properties of Nafion films.

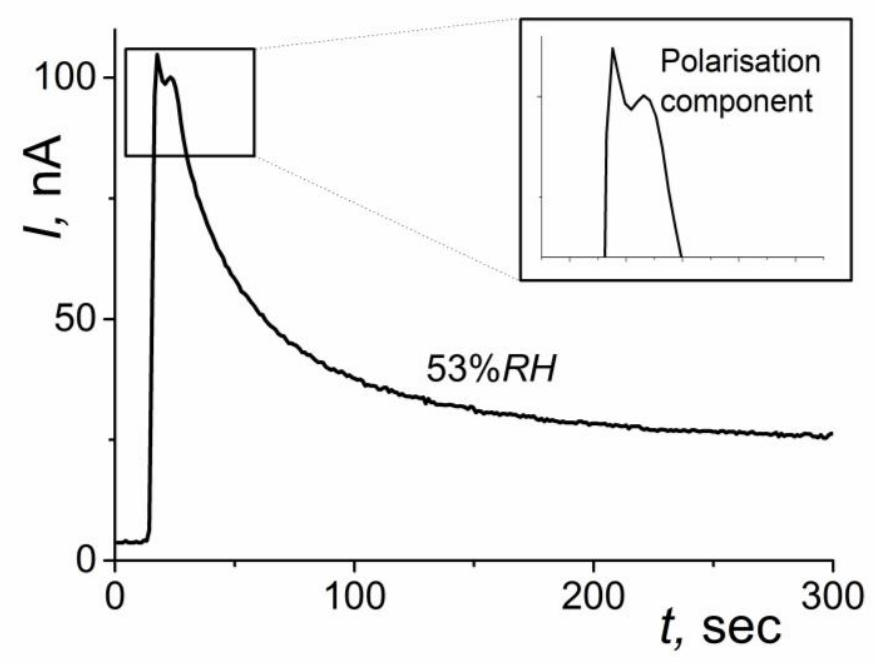

Figure16. Behavior of the current in the Nafion film when the measuring cell is transferred from a medium at $7 \%$ RH into water vapor at $53 \% R H(U=0.5 \mathrm{~V})$.

The dependence of the film conductivity on $R H$ was studied at low electrode voltages, when the current decay during the measurement was insignificant. Figure 17 shows the experimental curves of the behavior of the current in the measuring cell; Figure 17 shows the dependence of the current on $R H$ in logarithmic coordinates. According to Figure 17, the current (and, accordingly, conductivity) depends exponentially on $R H$. This dependence agrees with the data of [62-65] on the proton conductivity of Nafion membranes measured at different humidity values. However, the authors of these studies did not observe a strict linear dependence of the logarithm of proton conductivity on humidity, which is possibly associated with differences in the experimental conditions. The transfer of water in polar polymers at increased water vapor concentrations was considered in [66]. In these cases, Henry's law requires some correction because water in the polymer has the form of water clusters, but not molecular solution [67]; the clusters appear under experimental conditions, for example, in small-angle X-ray scattering experiments [68].

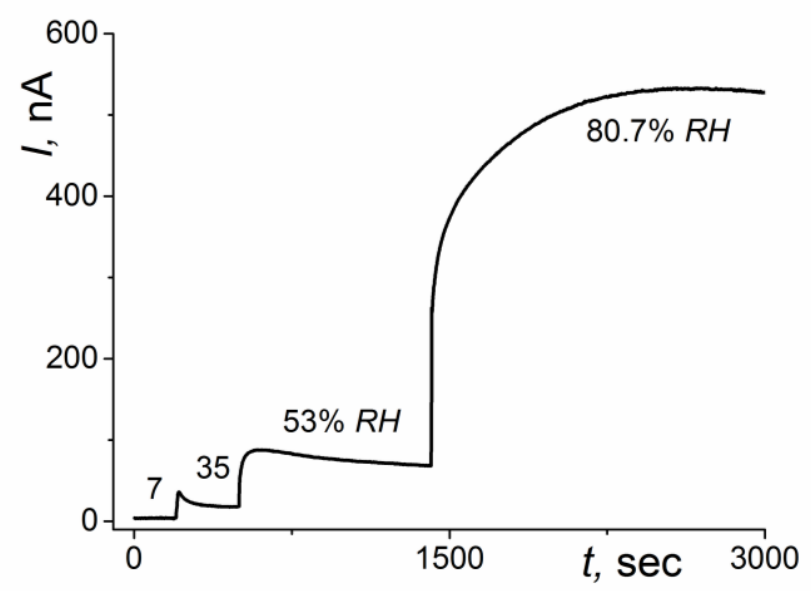

Figure17. Behavior of the current in the Nafion film as a function of humidity $(U=100 \mathrm{mV})$.

The theory of this process was considered in [69], and a semi-phenomenological expression was given for describing the diameter of the ion cluster in Nafion, whose typical diameter is $4 \mathrm{~nm}$. The clusters are connected by short channels (with a diameter of $\sim 1 \mathrm{~nm}$ ), and this cluster-chain model is thermodynamically stable. In this case, the ion transport in the membrane should be described by the percolation model, in which the bonding of ion clusters is critical. At high temperature and humidity, 
the conductivity in the polymer may be unstable. In our case, at room temperature this effect was observed at $R H>80 \%$ and electrode voltage $U>1 \mathrm{~V}$ (electric field strength $E>10 \mathrm{~V} / \mathrm{cm}$, Figure 18 ). Below $75 \% R H$, the current increases with humidity and then declines during long-term observation. When $R H$ further increases to $89 \%$, the current starts to increase noticeably with time; at $100 \% R H$, nonlinear effects appear, and at $U>1 \mathrm{~V}$, an electrical breakdown is observed, the current abruptly increasing to a high level. This is due to the formation of large water domains and conducting channels in the film; this model was considered in [70]. For Nafion membranes, this was already observed at $80^{\circ} \mathrm{C}$ and $95-100 \%$ RH [71]. The dependence of the proton conductivity of the Nafion film on electrode voltage is shown in Figure 19. When step voltage of $50 \mathrm{mV}$ is applied to a measuring cell, the current also increases stepwise, and the dependence of the current on voltage is linear. At the film thicknesses under study, in the absence of electric breakdown, the linear dependence in our case was observed up to $2 \mathrm{~V}$.

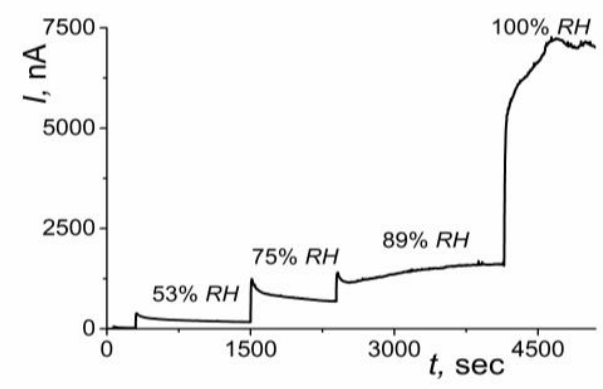

Figure18. Dependence of the current in the Nafion film at high relative humidity $(U=1 \mathrm{~V})$.

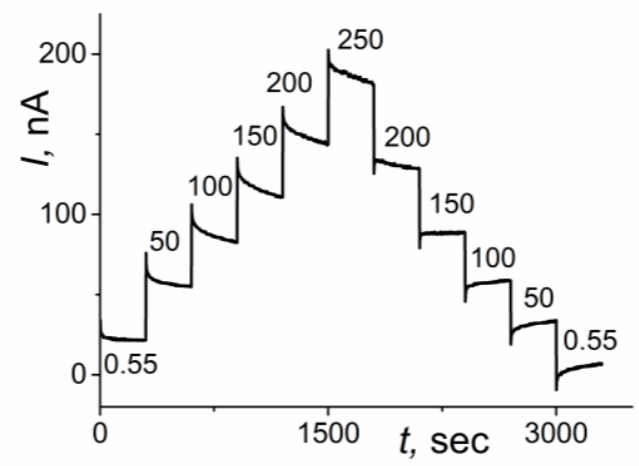

Figure19. Dependence of the current in the Nafion film on electrode voltage $(R H=35 \%)$.

The temperature dependence of proton conductivity of the Nafion film above $0^{\circ} \mathrm{C}$ is shown in Figure 20. The activation energy of proton conductivity of Nafion films in the temperature range $9-36^{\circ} \mathrm{C}$ is $E_{\mathrm{a}}=0.89 \pm 0.05 \mathrm{eV}\left(E_{\mathrm{a}}=85.7 \pm 5 \mathrm{~kJ} / \mathrm{mol}\right)$. For Nafion membranes pretreated in boiling water with various additives, the activation energy of proton conductivity is only $10.7 \mathrm{~kJ} / \mathrm{mol}$ [72]. In [62], the activation energy of proton migration at $R H 100 \%$ for Nafion membranes treated under different conditions was $1.1-1.8 \mathrm{~kJ} / \mathrm{mol}$. In our case, there was no preliminary thermal treatment of the Nafion films: they were dried under ambient conditions and placed before the measurements for 10-15 min in a dry atmosphere with $7 \% R H$.

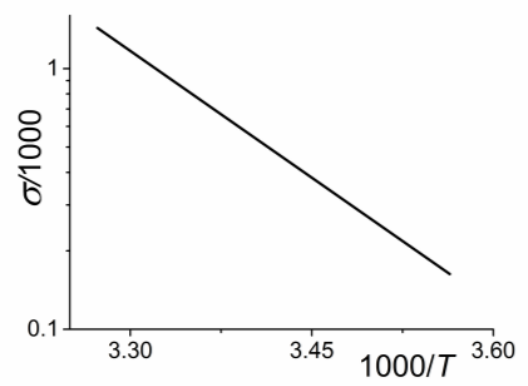

Figure20. Temperature dependence of the conductivity of the Nafion film in the range $7-36{ }^{\circ} \mathrm{C}(\mathrm{RH}=35 \%, U=$ $100 \mathrm{mV}$ ). 
As mentioned above (Figure 16), when a dry Nafion film was placed in a humid atmosphere, the polarization peak of conductivity first appeared mainly due to electron polarization and dipole polarization of water molecules trapped in the film. Let us consider the processes associated with further current decay during electric measurement. As mentioned above (Figures 16 and 17), the current decreases with time during the current passage through the Nafion film in water vapor, all other conditions (humidity, temperature, voltage) being equal. This behavior corresponds to a decrease in the diffusion coefficient of water molecules in the film, which is equivalent to film compaction during the measurement. This process depends on electrode voltage (current density), as shown in Figure 21.

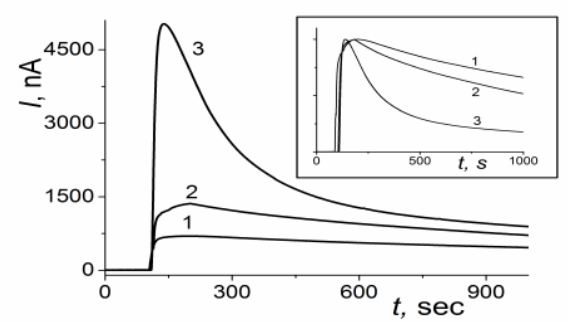

Figure21. Temporal profiles of current at different electrode voltages: (1) 0.1 , (2) 0.2 , and (3) $0.5 V(R H=$ $53 \%$ ). The same curves normalized to equal height are given in the insert.

As mentioned above, the morphology of Nafion films during hydration is usually considered based on the cluster-chain model $[31,67]$ : the film contains water clusters with a diameter of $\sim 4 \mathrm{~nm}$ connected by channels with a diameter of $\sim 1 \mathrm{~nm}$ and the same length; the water clusters contain acid groups attached to the polymer chains. Along with the cluster model, the model of parallel water channels in the Nafion membrane was proposed [73], which also quite adequately describes the current processes in the membrane. We believe that in our case, the polymer is dehydrated under the influence of current in a humid atmosphere, and, as a consequence, the cluster size or the diameter of water channels decreases, which is just responsible for the change in the film morphology (compaction).

\section{Electric Charge A CCUMulation and Storage in NAFion AND Graphene OXIDE}

\subsection{The effect of a dry-charged battery based on the graphene oxide and Nafion films}

In the measuring cell, which consists of two electrodes there is a proton current in a humid atmosphere as shown in Figure 22 for GO film (curve 1). Proton conductivity of GO and Nafion films depends on humidity and voltage on electrodes. Electrical characteristics of these films are similar. If one places the measurement cell in a dry atmosphere $(R H<7)$, the current drops to zero.

At the first stage (RH $<7 \%$ ), a voltage of $0.4 \mathrm{~V}$ was applied to the electrodes (Figure 22), and at $t \approx$ $200 s$ the sample was placed in a humid atmosphere $(R H=75 \%)$. An electric current observed for the sample (curve 1) is due to proton conductivity [10-12]. After some time ( 1300 s) the sample was transferred to a dry atmosphere, where it can be stored for a long time without applying voltage to the electrodes. If such a sample is placed in a humid atmosphere, then a negative current arises in the circuit with $U=0 \mathrm{~V}$, due to the neutralization of charges accumulated during the passage of a positive current at humidity of $R H=75 \%$. Note that after accumulation of charge and subsequent storage of the sample in a dry atmosphere $(R H<7 \%)$, the charge remains constant for a long time - up to several days as shown in Figure 23 (curve 3). Experimental results of this process are shown on the example of Nafion films (Figure 23) [75].

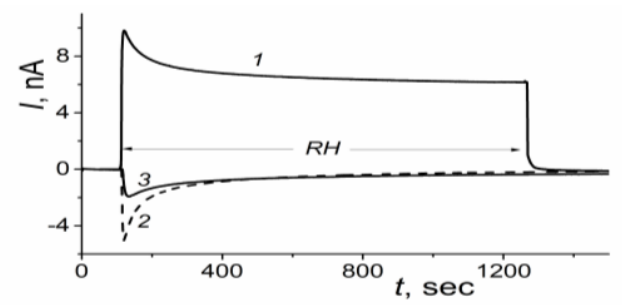

Figure22. The kinetics of proton current (curve 1) in GO layer $(R H=75 \%, U=0.4 \mathrm{~V})$. The kinetics of discharge current in GO layer in humid environment after charge storage in dry atmosphere for $0.5 \mathrm{~h}$ (curve 2) and $18 \mathrm{~h}$ (curve 3$)(\mathrm{RH}=75 \%, U=0 \mathrm{~V})$. 


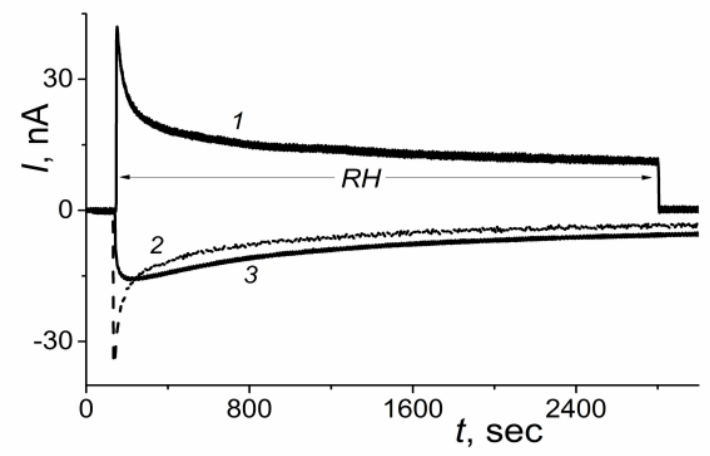

Figure23. Current-time (curve 1) in the Nafion film ( $R H=75 \%, U=0.5 \mathrm{~V})$. Discharging (curves 2-3) measured after storage at humidity of $R H<7 \%$ for $0.5 \mathrm{~h}$ (curve 2) and $70 \mathrm{~h}$ (curve 3) $(R H=75 \%, U=0 \mathrm{~V}$ ).

It should be noted that the type of charging and discharging curves substantially depends on the conditions of sample preparation. In a dry sample, after keeping it for more than a day at $R H \leq 7 \%$, both the charge and discharge occur more slowly. Such dependence is observed, for example, after 18 hours of charge sample storage in dry atmosphere (curve 3 in Figure 22), namely the maximum discharge current remarkably decreases, although the integrated discharge current decreases slightly, which can be seen from the slower discharge current decline to zero as compared to curve 2. Such dependencies seem to be natural, since GO film like other polymer films can swell in a humid atmosphere and change its morphology, while the accumulated charge in a dry atmosphere can be stored for a long time, for several days. The same changes are observed in the Nafion film when it stored in a dry atmosphere (Figure 23) - the discharge curves 2 and 3 are substantially smoothed for samples with prolonged charge storage. A change in the morphology of the GO film and its composition was observed in [12] when the film was stored in ambient environment. In that case a change in the composition of the epoxy/oxy groups was observed in GO films during the month of storage. The charging curve (curves 1 in Figure 22 and 23) has a characteristic feature with a maximum in the initial period and a gradual decrease in current to a stationary value in the course of measurement. Such behavior of the current can be explained by vacancies filling with protons from the negative electrode and electrons from the positive electrode.

The value of the accumulated charge (discharge current) is proportional to the charging current (as is seen in Figure 24). In the case of GO with a charging voltage of $0.4 \mathrm{~V}$ and a film thickness of about $0.4 \mu \mathrm{m}$, the charge is about $10^{-6} \mathrm{C}$. The charge maximum is limited by the concentration of traps in the GO layer (OH-groups) and can theoretically be $\sim 10^{-2} \mathrm{C}$. Note, the decrease in current of curve 1 (inset Figure 24) is comparable with the discharge current of curve 2 (insert Figure 24). In this case, their difference (the sum of curves 1 and 2) corresponds to the stationary current in the cell, as can be seen from curve 3 .

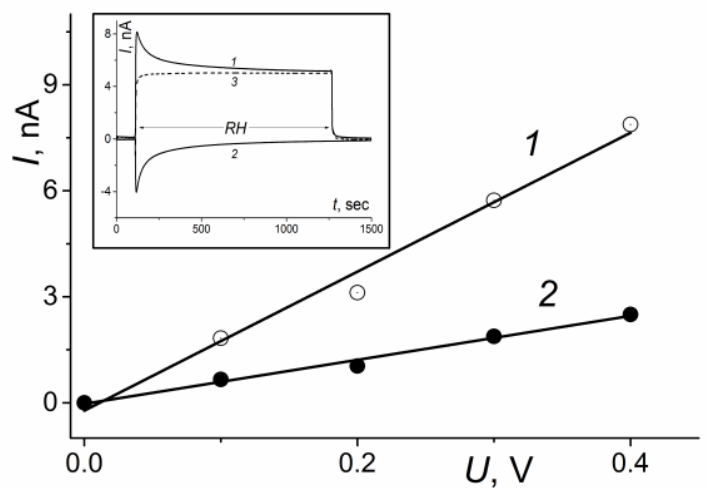

Figure24. 1 - Dependence of the charging current in GO film on the voltage applied to electrodes. 2 Dependence of the discharge current in the GO film at a voltage of $0 \mathrm{~V}$. (Insert: 1 - The kinetics of charge accumulation in $\mathrm{GO}$ film at $\mathrm{RH}=75 \%, U=0.4 \mathrm{~V} ; 2-$ The process of $\mathrm{GO}$ film discharge at $\mathrm{RH}=75 \%, U=0$ $V ; 3$ - The sum of curves 1 and 2).

The curves of charge-discharge of GO film are more smoothed with an increase in its thickness up to $500-600 \mathrm{~nm}$, which is explained by long time of water diffusion within the film. A significant 
increase in the charge-discharge time was observed with an increase in the film thickness up to $1 \mu \mathrm{m}$ while using GO as a sensor for humidity [13].

Such a value cannot be achieved in real conditions, since a large charge requires high currents and humidity. With high humidity and high voltage on the electrodes non-linear effects can occur - an uncontrolled increase in the current [74]. At these conditions, the cluster model of conductivity in GO films [30] is disturbed, the current increases uncontrollably, and electrical breakdowns occur, this is caused by the development of conducting water channels in GO film.

The processes of accumulation of charge and the kinetics of discharge in GO and Nafion films are identical, however, in the initial period of time there is some difference in the kinetics curves shown in Figure 25. The kinetics for GO films shows a more dramatic decrease in the discharge current than the kinetics for Nafion based films, which may be due to different proton diffusion coefficients in GO and Nafion films and different concentration of traps in films. It should be noted that protons of sulfogroups can be considered as traps (deep traps) in Nafion films, while in OG films the traps are presented with hydroxyl-groups (smaller traps).

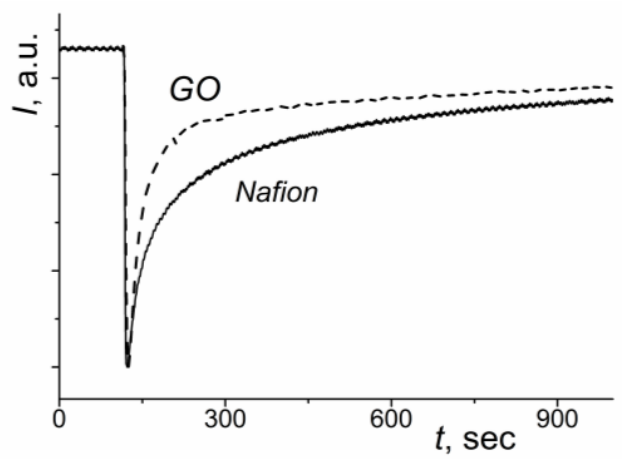

Figure25. Normalized curves of the discharge current in GO and Nafion films.

Discharge curves 1 and 2 in Figure 25 are not described by an exponential dependence and their behavior can be divided into two regions: in the initial period a sharp decrease in current is observed, and further behavior is close to the diffusion dependence.

\subsection{Effect of Humidity on Proton Conductivity in Graphene Oxide and Nafion Films}

GO and Nafion films are typical proton conductors in water vapor and their conductivity depends on the humidity of the environment. Figure 26 shows the behavior of the discharge current in Nafion (2) and GO (1) films in environments with different humidity and this dependence (current maximum) is a straight line in logarithmic coordinates $\log I=a(R H)$, where $a$ is a constant.

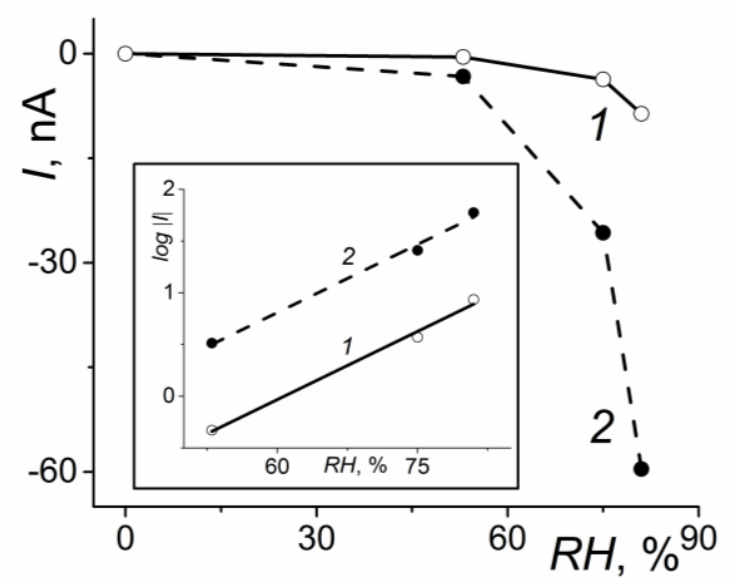

Figure26. The dependence of the maximum discharge current in the films of GO (1) and Nafion (2) on the RH. The inset shows the dependence of the current (maximum) on humidity in logarithmic coordinates.

Our results are consistent with the results of [63-65] on the dependence of proton conductivity of Nafion membranes on humidity but in the cited works there was no strict linear dependence of the logarithm of proton conductivity on humidity. 


\subsection{Model of Proton Diffusion with an Increase in Humidity}

The one-dimensional model for proton conductivity is considered in [9]. A proton trapped on a donor can jump to an acceptor at their significant approaching, and in our case this means a higher humidity. The semi-empirical potential EQ $(q)$ for proton transfer along hydrogen bond in the $\mathrm{R}-\mathrm{O}-\mathrm{H} \bullet \bullet \mathrm{O}-\mathrm{R}$ configuration for different distances $\mathrm{Q}$ between oxygen atoms ( $q$ is the proton coordinate) is shown in [9]. In our case, the distance between the oxygen atoms Q reflects the humidity of the sample and at distances of more than $300 \mathrm{pm}$ (low humidity) the barrier for proton hopping becomes more than 1 $\mathrm{eV}$, which virtually eliminates its diffusion in the absence of electric field.

The GO studied in our experiments had the following composition: $\mathrm{C}_{8} \mathrm{O}_{4.6} \mathrm{H}_{1.8}\left(\mathrm{H}_{2} \mathrm{O}\right)_{0.58}$, the density of GO film is $1.2 \mathrm{~g} / \mathrm{cm}^{3}$. The estimated average distance between oxygen atoms (without assigning it to any groups) is $0.416 \mathrm{~nm}(416 \mathrm{pm})$. Such a distance between oxygen atoms makes it impossible for protons to diffuse in a dry GO film, since the energy barrier exceeds $1 \mathrm{eV}$ [9]. In this case, the GO film is a high-resistance insulator in a dry atmosphere, since electronic conductivity is impossible due to the absence of double bonds in the $\mathrm{sp}^{3}$-hybridization of $\mathrm{GO}$, and proton conductivity is absent due to the large barrier between oxygen-containing groups - proton donors and acceptors. The number of oxy-groups in the GO is comparable to the number of epoxy-groups [12], and if we assume that only oxy-groups are involved in the proton transfer, then the distance between them is overestimated yet and the barrier for proton hopping will increase significantly. Proton conductivity can be assumed to occur at higher temperatures, as in many proton conductors [9], but this is impossible in practice, since graphene oxide is reduced to graphene structures at high temperatures and electronic conductivity appears.

Thus, the observed current behavior is similar to a charged capacitor, but unlike a capacitor, the charge in GO or Nafion films does not accumulate on the conductive elements, but directly in the film layer and in the dry atmosphere when a positive or negative potential is applied to the electrodes, and the current flows only in a humid atmosphere. This effect can also be compared to the behavior of a dry-charged battery, which is usually used for storing and transporting batteries in car service. In the case of acid batteries, the charge is stored as a chemical compound accumulated during the charge process. In our case, the charge is stored directly in the film layer without chemical conversion, which distinguishes it from acid batteries.

\section{CONCLUSiON}

1. GO films may exist in three distinctly different states: (a) without interlayer water, (b) with interlayer bound water, and (c) with both bound and free interlayer water. Upon drying of GO films at normal conditions, free water is retained in the film, thus giving rise to polarization current at $R H$ $100 \%$ for $U=0.1-10 \mathrm{~V}$. Upon drying of GO films at $R H 7 \%$, the bound water is retained and gives rise to proton conductivity. After complete removal of water, back penetration of water into the GO film is not observed even at $R H 100 \%$.

2. GO films can exhibit dual proton and electron conductivity. Proton conductivity shows the exponential dependence on relative humidity and temperature with the activation energy $E_{\mathrm{a}}=0.9 \pm$ $0.05 \mathrm{eV}$ at the temperature range $T>0^{\circ} \mathrm{C}$. For the electron conductivity $(220-273 \mathrm{~K})$ induced by thermolysis and chemical means $E_{\mathrm{a}}=1.15 \pm 0.05 \mathrm{eV}$. The GO films can be regarded as a first example of the mixed electron-proton conduction when sample conductivity can be regulated by external influence (humidity).

3. It was shown that at a certain degree of reduction the GO field-effect transistor can exhibit either proton or electron-hole conductivity. The transistor currents in the latter case exceed the protonconductivity currents by about three orders of magnitude. These phenomena can be used for controlling the transistor properties (for example, in sensor and probe circuits). At the same time, the environmental humidity may significantly affect the operation stability of a field effect transistor with GO used as an insulating layer.

4. The proton conductivity and the structure of the Nafion film are determined by the presence of free and bound water in it and the ratio between the amounts of these types of water. The extreme conditions of the film are completely dry and hydrated. After the Nafion film was dried at $7 \% R H$, bound water remains in the film, which contributes to the proton conductivity. In the presence of bound water in the Nafion film in water vapor, the coefficient of water diffusion into the film changes 
significantly under the influence of the current. This is associated with the removal of both free and bound water from the film when the current passes; Nafion does not undergo any chemical transformations, but the film morphology changes.

5. The possibility of accumulation and storage of charge in films of typical proton conductors was shown experimentally using GO and Nafion films. The amount of charge accumulation depends on the humidity of the environment. In a dry atmosphere the accumulated charge can be stored for up to several days. Accumulation of charge occurs directly in GO or Nafion film, which significantly distinguishes proton conductors from electric capacitors and liquid batteries.

\section{ACKNOWLEDGMENT}

We are thankful to Dr. R.A. Manzhos (IPCP RAS) and Dr. N.N. Denisov (IPCP RAS) for helpful discussions. The study was performed in accordance with the State Assignment (no. 0089-20190012). The work was financially supported by the RSF (no. 17-73-20236). The study has been performed using the equipment of the MUAC of IPCP RAS.

\section{REFERENCES}

[1] Allen M.J., Tung V.C., Kaner R.B. Honeycomb carbon: a review of graphene. Chem. Rev. 2010, 110, $132-145$.

[2] Zhang Y.-L., Guo L., Xia H., Chen Q.-D., Feng J., Sun H.B. Photoreduction of graphene oxides: methods, properties, and applications. Adv. Optical Mater. 2014, 2, 10-28.

[3] Singh V., Joung D., Zhai L., Das S., Khondaker S.I., Seal S. Graphene based materials: past, present and future. Progress in Mater. Sci. 2011, 56, 1178-1271.

[4] Zhu Y., Murali S., Cai W., Li X., Suk J.W., Potts J.R., Ruoff R.S. Graphene and graphene oxide: synthesis, properties and applications. Adv. Mater. 2010, 22, 3906-3924.

[5] Wu Z.S., Parvez K., Feng X., Müllen K. Graphene-based in-plane micro-supercapacitors with high power and energy densities. Nat. Commun. 2013, 4, 2487(8 pp.).

[6] Pumera M. Electrochemistry of graphene, graphene oxide and other graphenoids: review, Electrochem. Commun. 2013, 36, 14-18.

[7] Perrozzi F, Prezioso S, Ottaviano L. Graphene oxide: from fundamentals to applications. J. Phys. Condens. Matter. 2015, 27, 013002(21 pp.).

[8] Fang Y.J., Wang H.J., Yu H., Peng F. From chicken feather to nitrogen and sulfur co-doped large surface bio-carbon flocs: an efficient electrocatalyst for oxygen reduction reaction. Electrochim. Acta. 2016, 213, 273-282.

[9] Kreuer K.-D. Proton conductivity: materials and applications. Chem. Mater. 1996, 8, 610-641.

[10] Yao Y., Chen X., Zhu J., Zeng B., Wu Z., Li X. The effect of ambient humidity on the electrical properties of graphene oxide films. Nanoscale Reseasch Letters. 2012, 7, 363(7 pp.).

[11] Shulga Y.M., Martynenko V.M., Muradyan V.E., Baskakov S.A., Smirnov V.A., Gutsev G.L. Gaseous products of thermo- and photo-reduction of graphite oxide. Chemical Physics Letters. 2010, 498, 287-291.

[12] Kim S., Zhou S., Hu Y., Acik M., Chabal Y.J., Berger C., de Heer W., Bongiorno A., Riedo E. Roomtemperature metastability of multilayer graphene oxide films. Nature Materials. 2012, 11, 544-549.

[13] Karim M.R., Hatakeyama K., Matsui T., Koinuma M., Matsumoto Y., Akutagawa T., Nakamura T., Noro S., Yamada T., Kitagawa H., Hayami S. Graphene oxide nano sheet with high proton conductivity. J. Am. Chem. Soc. 2013, 135, 8097-8100.

[14] Borini S., White R., Wei D., Astley M., Haque S., Spigone E., Harris N., Kivioja J., Ryhänen T. Ultrafast graphene oxide humidity sensors. ACS Nano. 2013, 7, 11166-11123.

[15] Repp S., Harputlu E., Gurgen S., Castellanoa M., Kremer N., Pompe N., Wörner J., Hoffmann A., Thomann R., Emen F.M., Weber S., Ocakoglub K., Erdem E. Synergetic effects of $\mathrm{Fe}^{3+}$ doped spinel $\mathrm{Li}_{4} \mathrm{Ti}_{5} \mathrm{O}_{12}$ nanoparticles on reduced graphene oxide for high surface electrode hybrid supercapacitors. Nanoscale. 2018, 10, 1877-1884.

[16] Tran M.-H., Jeong H.K. Ternary carbon composite films for supercapacitor applications. Chemical Physics Letters. 2017, 684, 1-7.

[17] Smirnov V.A., Mokrushin A.D., Vasiliev V.P., Denisov N.N., Denisova K.N. Mixed proton and electron conduction in graphene oxide films: field effect in a transistor based on graphene oxide. Applied Physics A. $2016,122,513(8$ pp.). 
[18] Thimmappa R., Fawaz M., Devendrachari M.C., Gautam M., Kottaichamy A.R., Shafi S.P., Thotiy M.O. Anisotropic amplification of proton transport in proton exchange membrane fuel cells. Chemical Physics Letters. 2017, 679, 1-5.

[19] Huang Y., Cheng T., Zhang X., Zhang W., Liu X. Novel composite proton exchange membrane with longrange proton transfer channels constructed by synergistic effect between acid and base functionalized graphene oxide. Polymer. 2018, 149, 305-315.

[20] Feng M., Huang Y., Cheng Y., Liu J., Liu X. Rational design of sulfonated poly(ether ether ketone) grafted graphene oxide-based composites for proton exchange membranes with enhanced performance. Polymer. 2018, 144, 7-17.

[21] Feng M., Huang Y., Wei M., Liu X. Sulfonated poly(arylene ether nitrile)-based hybrid membranes containing amine-functionalized GO for constructing long-range ionic nanochannels. International Journal of Hydrogen Energy. 2018, 43, 11214-11222.

[22] Gao W., Singh N., Song L., Liu Z., Reddy A.L., Ci L., Vajtai R., Zhang Q., Wei B., Ajayan P.M. Direct laser writing of micro-supercapasitor on hydrated graphite oxide films. Nat. Nanotechnol. 2011, 6, 496-500.

[23] Wang L., Lee K., Sun Y.-Y., Lucking M., Chen Z., Zhao J.J., Zhang SB. Graphene oxide as an ideal substrate for hydrogen storage. ACS Nano. 2009, 3, 2995-3000.

[24] Buchsteiner A., Lerf A., Pieper J. Water dynamics in graphite oxide investigated with neutron scattering. J. Phys. Chem. B. 2006, 110, 22328-22338.

[25] Talyzin A.V., Luzan S.M., Szabo T., Chernyshev D., Dmitriev V. Temperature dependent structural breathing of hydrated graphite oxide in $\mathrm{H}_{2} \mathrm{O}$. Carbon. 2011, 49, 1894-1899.

[26] Zhu J., Andres C.M., Xu J., Ramamoorthy A., Tsotsis T., Kotov N.A. Pseudonegative thermal expansion and the state of water in graphene oxide layered assemblies. ACS Nano. 2012, 6, 8357-8365.

[27] Smirnov V.A., Denisov N.N., Ukshe A.E., Shul'ga Yu.M. Effect of humidity on the conductivity of graphite oxide during its photoreduction. High Energy Chemistry. 2013, 47, 242-246.

[28] Smirnov V.A., Denisov N.N., Ukshe A.E., Shul'ga Yu.M. Conductivity of graphene oxide films: dependence from solvents and photoreduction. Chem. Phys. Lett. 2013, 583, 155-159.

[29] Alberti G., Casciola M., Massinelli L., Bauer B. Polymeric proton conducting membranes for medium temperature fuel cells (110-160 $\left.{ }^{\circ} \mathrm{C}\right)$. J. Membrane Sci. 2001, 185, 73-81.

[30] Hickner M.A., Ghassemi H., Kim Yu.-S., Einsla B.R., McGrath J.E. Alternative polymer systems for proton exchange membranes (PEMs). Chem. Rev. 2004, 104, 4587-4612.

[31] Mauritz K.A., Moore R.B. State of understanding of Nafion. Chem. Rev. 2004, 104, 4535-4586.

[32] Negro E., Vittadello M., Vezzùd K., Paddison S.J., Di Noto V. The influence of the cationic form and degree of hydration on the structure of Nafion ${ }^{\mathrm{TM}}$. Solid State Ionics. 2013, 252, 84-92.

[33] Yu J., Lian Y., Xu W., Wang C., Chang X., Tang T.B., Gu M. Proton conductance and dielectric relaxation in hydrated graphite oxide, studied with impedance spectroscopy. Appl. Phys. Lett. 2018, 112, 171603(4 pp.).

[34] Riess I. Mixed ionic-electronic conductors - material properties and applications. Solid State Ion. 2003, $157,1-17$.

[35] Inzelt G., Pineri M., Schultze J.W., Vorotyntsev M.A. Electron and proton conducting polymers: recent developments and prospects. Electrochim. Acta. 2000, 45, 2403-2421.

[36] Costantini N., Wegner G., Mierzwa M., Pakula T. Simultaneous ionic and electronic conductivity in polymeric materials. Macromol. Chem. Phys. 2005, 206, 1345-1354.

[37] Aragaw B.A., Su W.-N., Ricka J., Hwang B.-J. Highly efficient synthesis of reduced graphene oxideNafion nanocomposites with strong coupling for enhanced proton and electron conduction. RSC Adv. 2013, 3, 23212-23221.

[38] Tortello M., Bianco S., Ijeri V., Spinelli P.S., Tresso E. Nafion membranes with vertically-aligned CNTs for mixed proton and electron conduction. J. Membrane Sci. 2012, 415-416, 346-352.

[39] Oberoi A., Andrews J. Metal hydride-Nafion composite electrode with dual proton and electron conductivity. Int. J. Smart Grid and Clean Energy. 2014, 3, 270-274.

[40] Novoselov K.S., Geim A.K., Morozov S.V., Jiang D., Zhang Y., Dubonos S.V., Grigorieva I.V., Firsov A.A. Electric field effect in atomically thin carbon films. Science. 2004, 306, 666-669.

[41] Lemme M.C. Current status of graphene transistors. Solid State Phenomena. 2010, 156-158, 499-509.

[42] Schwierz F. Graphene transistors. Nature nanotechnol. 2010, 5, 487-496.

[43] Castro Neto A.H., Guinea F., Peres N.M.R., Novoselov K.S., Geim A.K. The electronic properties of graphene. Rev. Mod. Phys. 2009, 81, 109-162 
[44] Luo Z., Lu Y., Somers L.A., Johnson A.T.C. High yield preparation of macroscopic graphene oxide membranes. J. Am. Chem. Soc. 2009, 131, 898-899.

[45] Chen J.-H., Jang C., Xiao S., Ishigami M., Fuhrer M.S. Intrinsic and extrinsic performance limits of graphene devices on $\mathrm{SiO}_{2}$. Nature nanotechnol. 2008, 3, 206(9 pp.).

[46] Childres I., Jauregui L.A., Foxe M., Tian J., Jalilian R., Jovanovic I., Chen Y.P. Effect of electron-beam irradiation on graphene field effect devices. Appl. Phys. Lett. 2010, 97, 173109(3 pp.).

[47] Antonova I.V., Kotin I.A., Nebogatikova N.A., Prinz V.Y.A. Modulation of current in self-forming lateral graphene-based heterostructures. Technical phys. Lett. 2015, 41, 950-953.

[48] Eda G., Nathan A., Wöbkenberg P., Colleaux F., Ghaffarzadeh K., Anthopoulos T.D., Chhowalla M. Graphene oxide gate dielectric for graphene-based monolithic field effect transistors. Appl. Phys. Lett. 2013, 102, 133108(4 pp.).

[49] Standley B., Mendez A., Schmidgall E., Bockrath M. Graphene-graphite oxide field-effect transistors. Nano Lett. 2012, 12, 1165-1169.

[50] Lee S.-K., Jang H.Y., Jang S., Choi E., Hong B.H., Lee J., Park S., Ahn J.-H. All graphene-based thin film transistors on flexible plastic substrates. Nano Lett. 201, 12, 3472(6 pp.).

[51] Toh S.Y., Loh K.S., Kamarudin S.K., Wan Daud W.R. Graphene production via ecectrochemical reduction of graphene oxide: synthesis and characterization. Chem. Eng. J. 2014, 251, 422-434.

[52] Stankovich S., Piner R.D., Chen X., Wu N., Nguyen S.T., Ruoff R.S. Stable aqueous dispersions of graphitic nanoplatelets via the reduction of exfoliated graphite oxide in the presence of poly(sodium 4styrenesulfonate). J. Mater. Chem. 2006, 16, 155-158.

[53] Kim K., Park H.J., Woo B.-C., Kim K.J., Kim G.T., Yun W.S. Electric property evolution of structurally defected multilayer graphene. NANO Lett. 2008, 8, 3092-3096.

[54] Jung I., Vaupel M., Pelton M., Piner R., Dikin D.A., Stankovich S., An J., Ruoff R.S. Characterization of thermally reduced graphene oxide by imaging ellipsometry. J. Phys. Chem. C. 2008, 112, 8499-8506.

[55] Smirnov V.A., Denisov N.N., Dremova N.N., Vol'fkovich Y.M., Rychagov A.Y., Sosenkin V.E., Belay .KG., Gutsev G.L., Shulga N.Yu., Shulga Y.M. A comparative analysis of graphene oxide films as proton conductors. Appl. Phys. A. 2014, 117, 1859-1863.

[56] Kumar R., Mamlouk M., Scott K. A graphite oxide paper polymer electrolyte for direct methanol fuel cells. Int. J. Electrochem. 2011, Article ID 434186(7 pp.).

[57] Hu S., Lozada-Hidalgo M., Wang F.C., Mishchenko A., Schedin F., Nair R.R., Hill E.W., Boukhvalov D.W., Katsnelson M.I., Dryfe .RA.W., Grigorieva I.V., Wu H.A., Geim A.K. Proton transport through one-atom-thick crystals. Nature. 2014, 516, 227-230.

[58] Kunst M., Warman J.M. Proton mobility in ice. Nature. 1980, 288, 465-467.

[59] Fallahazad B., Lee K., Lian G., Kim S., Corbet C.M., Ferrer D.A., Colombo L., Tutuc E. Scaling of $\mathrm{Al}_{2} \mathrm{O}_{3}$ dielectric for graphene field-effect transistors. Appl. Phys. Lett. 2012, 100, 093112.

[60] Zhong C., Deng Y., Roudsari A.F., Kapetanovic A., Anantram M.P., Rolandi M. A polysaccharide bioprotonic field-effect transistor. Nature Commun. 2011, 2, 476-481.

[61] Riskey K.L. Fabrication and characterization of a solid-state ambipolar ionic field-effect transistor. A thesis for the degree of Master of Science. 2013.

[62] Sone Y., Ekdunge P., Simonsson D. Proton conductivity of Nafion 117 as measured by a four-electrode AC impedance method. J. Electrochem. Soc. 1996, 143, 1254-1259.

[63] Alonso R.H., Estevez L., Lian H., Kelarakis A., Giannelis E.P. Nafion-clay nanocomposite membranes: morphology and properties. Polymer. 2009, 50, 2402-2410.

[64] Seesukphronrarak S., Ohira A. Novel highly proton conductive sulfonated poly(p-phenylene) from2,5-dichloro4-(phenoxypropyl)benzophenone as proton exchange membranes for fuel cell applications. Chem. Commun. 2009, 31, 4744-4746.

[65] Ochi S., Kamishima O., Mizusaki J., Kawamura J. Investigation of proton diffusion in Nafion®117 membrane by electrical conductivity and NMR. Solid State Ionics. 2009, 180, 580-584.

[66] Williams J.L., Hoppenberg H.B., Stannett V. Water transport and clustering in poly[vinyl cloride], poly[oxymethylene], and other polymers. J. Macromol. Sci. B. 1969, 3, 711-725.

[67] Gierke T.D., Munn G.E., Wilson F.C. The morphology in Nafion ${ }^{\dagger}$ perfluorinated membrane products, as determined by wide- and small-angle X-ray studies. J. Polym. Sci. B. 1981, 19, 1687-1704.

[68] Fujimura M., Hashimoto T., Kawai H. Small-angle X-ray scattering study of perfluorinated ionomer membranes. 1. Origin of two scattering maxima. Macromolecules. 1981, 14, 1309-1315.

[69] Hsu W.Y., Gierke T.D. Ion transport and clustering in nafion per fluorinated membranes. J. Membrane Sci. 1983, 13, 307-326. 
[70] Majsztrik P., Bocarsly A., Benziger J. Water permeation through nafion membranes: the role of water activity. J. Phys. Chem. B. 2008, 112, 16280-16289.

[71] Alberti G., Narducci R., di Vona M.L., Giancola S. More on Nafion conductivity decay at temperatures higher than $80{ }^{\circ} \mathrm{C}$ : preparation and first characterization of in-plane oriented layered morphologies. Ind. Eng. Chem. Res. 2013, 52, 10418-10424.

[72] Onishi L.M., Prausnitz J.M., Newman J. Water-Nafion equilibria. Absence of schroeder's paradox. J. Phys. Chem. B. 2007, 111, 10166-10173.

[73] Schmidt-Rohr K., Chen Q. Parallel cylindrical water nanochannels in Nafion fuel-cell membranes. Nat. Mater. 2008, 7, 75-83.

[74] Smirnov V.A., Dubovitskii V.A., Denisov N.N., Vasiliev V.P., Dobrovolskii Yu.A. Effect of external electric field on the proton conductivity of Nafion films. Russ. J. Phys. Chem. B. 2018, 12, 475-484.

[75] Vasiliev V.P., Smirnov V.A. Electric charge accumulation and storage in Nafion and graphene oxide films. Chemical Physics Letters. 2019, 726, 99-103.

Citation: Vladimir Vasiliev, Vyacheslav Smirnov, "A Review on the Conductive Properties of Graphene Oxide Films”, International Journal of Advanced Research in Chemical Science, vol. 6, no. 11, p. 12-32, 2019. DOI: http://dx.doi.org/10.20431/2349-0403.0611002

Copyright: (c) 2019 Authors. This is an open-access article distributed under the terms of the Creative Commons Attribution License, which permits unrestricted use, distribution, and reproduction in any medium, provided the original author and source are credited. 